\title{
LONG-TERM EFFECTS OF THE 1959-1961 CHINA FAMINE: MAINLAND CHINA AND HONG KONG
}

\author{
Douglas Almond \\ Lena Edlund \\ Hongbin Li \\ Junsen Zhang \\ Working Paper 13384 \\ http://www.nber.org/papers/w13384 \\ NATIONAL BUREAU OF ECONOMIC RESEARCH \\ 1050 Massachusetts Avenue \\ Cambridge, MA 02138 \\ September 2007
}

We would like to thank Janet Currie, Andrew Gelman, Hilary Hoynes, Robert Kaestner, Nancy Qian, Mark Rosenzweig, David St. Clair, Jane Waldfogel, and David Wise for helpful comments. Holly Ho Ming and Hongyan Zhao provided outstanding research assistance. Almond thanks the Fulbright Program and Edlund the Russell Sage Foundation for financial support. The views expressed herein are those of the author(s) and do not necessarily reflect the views of the National Bureau of Economic Research.

(C) 2007 by Douglas Almond, Lena Edlund, Hongbin Li, and Junsen Zhang. All rights reserved. Short sections of text, not to exceed two paragraphs, may be quoted without explicit permission provided that full credit, including $(\mathrm{C}$ notice, is given to the source. 
Long-Term Effects Of The 1959-1961 China Famine: Mainland China and Hong Kong Douglas Almond, Lena Edlund, Hongbin Li, and Junsen Zhang

NBER Working Paper No. 13384

September 2007

JEL No. I10,I12,J12,J13,J16,J24,P2

\begin{abstract}
This paper estimates the effects of maternal malnutrition exploiting the 1959-1961 Chinese famine as a natural experiment. In the $1 \%$ sample of the 2000 Chinese Census, we find that fetal exposure to acute maternal malnutrition had compromised a range of socioeconomic outcomes, including: literacy, labor market status, wealth and marriage market outcomes. Women married spouses with less education and later, as did men, if at all. In addition, maternal malnutrition reduced the sex ratio (males to females) in two generations -- those prenatally exposed and their children -- presumably through heightened male mortality. This tendency toward female offspring is interpretable in light of the Trivers-Willard (1973) hypothesis, according to which parents in poor condition should skew the offspring sex ratio toward daughters. Hong Kong natality micro data from 1984-2004 further confirm this pattern of female offspring among mainland-born residents exposed to malnutrition in utero.

Douglas Almond

Department of Economics and SIPA

Columbia University

International Affairs Building, MC 3308

420 West 118th Street

New York, NY 10027

and NBER

da2152@columbia.edu

Lena Edlund

Columbia University

420 West 118th Street, Rm. 1022 IAB

MC 3323

New York, NY 10027

Hongbin Li

Department of Economics

Chinese University of Hong Kong

Shatin, N.T.

Hong Kong

and Tsinghua University

lihongbin@sem.tsinghua.edu.cn

Junsen Zhang

Department of Economics

Chinese University of Hong Kong

Shatin, N.T.

Hong Kong

jszhang@cuhk.edu.hk
\end{abstract}

le93@columbia.edu 


\section{Introduction}

China's Great Leap Forward caused the worst famine in recorded history, with between 16.5 and 30 million deaths [Li and Yang, 2005]. Some 40 years on, the famine's 1960 peak provides a natural experiment for evaluating the long-term effects of fetal nutrition.

Focus on the prenatal period is motivated by a growing literature suggesting that health in adulthood may be "programmed" in utero, a linkage popularized by Barker [1992]. The prevalence of maternal malnutrition in developing countries (e.g., DeRose et al. [2000]) makes this a relationship of continuing relevance. That socioeconomic outcomes respond to fetal health - as our results will indicate - may help explain the strong correlation between health and socioeconomic outcomes apparent at both the individual and national levels [Case et al., 2002, Cutler et al., 2006]. Improvements in fetal nutrition, therefore, may offer the twin benefits of improving future health and economic outcomes.

Evidence on the causal effects of fetal nutrition, however, is surprisingly scarce (see e.g., Rasmussen [2001], Walker et al. [2007]). The Chinese famine (henceforth the Famine) reduces the scope for omitted factors (e.g., parental abilities) that might generate positive associations between measures of fetal health and adult socioeconomic outcomes in the absence of a causal pathway.

Observing cohorts born 1956-64 in the 2000 Chinese Population Census, we find that men were $9 \%$ more likely to be illiterate, $6 \%$ less likely to work, and $6.5 \%$ less likely to be married if exposed to the Famine in utero. Women were $7.5 \%$ more likely to be illiterate and $3 \%$ less likely to work, 
and tended to marry men with less education. We also find fetal exposure to the Famine substantially reduced the cohort's sex ratio (fewer males), suggesting greater male vulnerability to maternal malnutrition. Perhaps most intriguing, we find an "echo effect" of the Famine on the next generation: children whose mothers were exposed prenatally also registered Famine impacts. In particular, Famine-exposed mothers were more likely to give birth to daughters. To our knowledge, ours is the first study to trace the offspring sex ratio to the in utero environment of the parent.

While comparisons within a narrow birth interval (1956-64) help reduce the potential for confounding, our "control" groups were not untouched by the Famine: the older cohorts experienced it directly as infants and toddlers and the younger cohorts were the children of Famine survivors. Moreover, both rural and urban residents experienced famine. The difficulty in finding a suitable control group motivates two additional approaches. First, we utilize variation in Famine severity by province to generate comparisons within birth cohorts. Second, while the Famine was endemic in mainland China, Hong Kong, then a British colony, was spared. The Famine resulted in a large inflow of mainland Chinese into Hong Kong. Since Hong Kong Natality data include information on the birth place of the parents, we can compare mainland born and Hong Kong born mothers in these data. Results from these two additional approaches corroborate the findings in the Census data: damage to a broad spectrum of outcomes persists 40 years after the Famine's end.

The remainder of the paper is organized as follows. Sections 1.1-1.3 describe the background of the Famine and review the previous Famine 
literature. Section 2 describes the 2000 Chinese Population Census and the 1984-2004 Hong Kong Natality files. Section 3 reports descriptive and regression results, along with a discussion of potential biases. Section 4 concludes.

\subsection{Famine background}

The Famine began in the fall of 1959 and impacted all regions of China. Grain output dropped 15\% in 1959 and another 15\% in 1960 [Li and Yang, 2005, page 846]. By 1962, birth and death rates had returned to normal levels.

While weather conditions contributed to the Famine, the radical economic policies of the Great Leap Forward were chiefly to blame [Lin, 1990, Li and Yang, 2005]. In a breakneck attempt to overtake Britain and eventually the U.S., labor was diverted from agriculture to industry while grain procurement from rural areas was increased. At the same time, collectivization of agricultural production resulted in shirking and falling productivity [Lin, 1990]. The political climate encouraged provincial leaders to overstate grain production. Despite widespread starvation, China was a net exporter of grain throughout 1960 [Yao, 1999, Lin and Yang, 2000].

Famine intensity varied by region [Peng, 1987]. Rural death rates rose to 2.5 times pre-Famine levels. Urban residents fared better but were not spared, death rates in the peak year 1960 were $80 \%$ above pre-Famine levels [China Statistical Press, 2000]. Central provinces such as Anhui, Henan and Sichuan were the worst hit, while northeastern provinces such 
as Heilongjiang and Jilin were relatively spared. By 1961, death rates had returned to normal in more than half of the provinces, but remained high in, for instance, the southern provinces Guangxi and Guizhou (close to Hong Kong).

\subsection{Famine studies: Epidemiology}

The best epidemiological evidence to date linking maternal nutritional deprivation to subsequent adult outcomes derives from the cohort in utero during the 1944-45 Dutch famine. While the seminal study found limited effects at age 18 [Stein et al., 1975], at middle age, this cohort exhibited a broad spectrum of damage including: self-reported health [Roseboom et al., 2001b], coronary heart disease morbidity [Roseboom et al., 2001b, Bleker et al., 2005], and adult antisocial personality disorders [Neugebauer et al., 1999]. These, and studies of the 1866-1868 Finnish Famine and the Nazi Seige of Leningrad, have focused exclusively on health outcomes. Epidemiological findings from the Chinese Famine include heightened risk of schizophrenia [Clair et al., 2005] and obesity among women [Luo et al., 2006].

\subsection{Famine studies: Economics}

A number of recent studies evaluating the Famine's impact on the socioeconomic outcomes of survivors have used the China Health and Nutrition Surveys (CHNS) [Chen and Zhou, 2007, Meng and Qian, 2006, Gorgens et al., 2005]. The CHNS is a panel dataset that began in 1989 of health and economic outcomes of approximately 4,000 Chinese households from nine 
provinces (out of 31 provinces or province level administrative regions). The small sample size combined with the collapse of fertility during the Famine necessitates the inclusion of ages well after birth as "treated." ${ }^{1}$ However, broad "early childhood" hypotheses makes it difficult to reject alternative explanations. The possibility then that events at other ages for instance the subsequent Cultural Revolution and the forced "rustification" of students in outlying areas - confounds results is a concern.

Chen and Zhou [2007] considered those up to age 6 as treated. They proxied Famine intensity by the province level death rate in 1960 and found the Famine thus measured to have resulted in stunting of those born in $1955,1957,1959,1960$ and 1962, with the largest height reductions for the 1959, 1960, and 1962 birth cohorts. In an analogous specification, they found reduced labor supply of those born in 1959 and 1960, and lower wealth as measured by the size of residence for birth cohorts 1958 and 1959.

Meng and Qian [2006] considered the following birth cohorts as potentially affected: 1952-54, 1955-58, 1959-60, with cohorts born 1961-64 as the reference group. Using reductions in cohort size as a proxy for Famine severity (assumed to occur through Famine mortality), their OLS estimation returned mixed results, and little evidence for a particularly strong effect for the 1959-60 cohort. Instrumenting for cohort size, using per capita grain production in 1997, they found a small negative effects on education, but a substantial $(25 \%)$ reduction in hours worked for the

\footnotetext{
${ }^{1} 105$ rural CHNS respondents and 62 urban CHNS respondents were born in 1960, with 66 and 45 respectively in 1961 [Chen and Zhou, 2007] table 2.
} 
1959-60 cohort.

Gorgens et al. [2005] studied adult heights of cohorts exposed to the Famine in childhood using the CHNS data. They argued both that children who survived the Famine did not show any stunting and that stunting did occur. They reconcile these two arguments by a third: Famine mortality was concentrated among shorter people. The net effect of stunting and selection, the authors argued, made the height of survivors appear unchanged. However, the claim that no stunting is observed among survivors is controversial [Chen and Zhou, 2007, Yan, 1999, Morgan, 2006].

\section{Data}

Our primary data set is 2000 Population Census of China. ${ }^{2}$ The $1 \%$ sample includes more than 11 million records and has not (to our knowledge) been used to evaluate long-term effects of the Famine. ${ }^{3}$ Outcomes include educational attainment, labor market status, and residence information of respondents. Demographic information includes sex, birth year and month, marriage and fertility information.

Unlike preceding Census surveys and the CHNS data, the 2000 Census records the province of birth, eliminating the potential for confounding due to internal migration. ${ }^{4}$ The 2000 Census captures Famine cohorts near age 40, and therefore near the flat portion of their occupation and earnings

\footnotetext{
${ }^{2}$ Conducted by the Chinese National Bureau of Statistics for mainland China.

${ }^{3}$ Shi [2006] used a $0.1 \%$ sub-sample of the 2000 Census.

${ }^{4} 6 \%$ of those born 1956-64 reported moving from another province since birth, with another $10 \%$ relocating towns within the province of birth.
} 
profile. Moreover, it is the first Census to capture near-complete fertility histories of women born during the Famine. ${ }^{5}$ We restrict analysis to those born 1956-1964, a sub-sample which includes three pre-Famine years and three post-Famine years (Death rates peaked in 1960 but were elevated in 1959 and 1961 as well, see Figure 1). Our relatively narrow birth interval is intended to increase the similarity of the unobserved, later-life factors and their effects on Census outcomes.

Our second data source is the natality microdata for Hong Kong (19842004), derived from the universe of birth certificates. These data include information on maternal country of birth. Restricting the sample to mothers of singletons either born in mainland China or Hong Kong in the years 1957-1965 yields some 600,000 records, approximately one-third of whom emigrated from the mainland. The Hong Kong data provide an important control group since all of mainland China (rural and urban) was afflicted by the Famine [Cai and Feng, 2005].

\subsection{Measuring the Famine}

We use two measures of famine intensity: death rates and average month of birth.

Death rates We use the all-age death rate [China Statistical Press, 2000] by year and province to calculate two (mortality-based) proxies of Famine intensity. We have data for 29 out of the 31 provinces (or province level divisions).

${ }^{5} .3 \%$ of women born in 1960 reported having a child between November 1999 and October 2000, versus $14.8 \%$ for women born in 1976 (the maximum). 
- First, for every person, we calculate the weighted average of the death rate in the province of birth for the duration of the fetal period, henceforth "weighted death rate" or $\mathbf{w d r}_{j t}$. For example, a person born in January 1960 in Beijing is assigned 1/9th of Beijing's 1960's mortality rate and 8/9th of Beijing's 1959's mortality rate. This weighted death rate ranged from 0.005 to 0.069 (per person).

- Second, we collapse this weighted death rate by month of birth, thus calculating a population weighted national average for each month and year, henceforth "aggregate weighted death rate" or $\mathbf{a w d r}_{t}$. During the study period, this measure ranged from 0.010 (in 1963) to 0.022 (at the end of 1960), a difference of 0.012. Thus measured, those born towards the end of 1960, and early 1961, were exposed to the greatest Famine intensity in utero, Figure 1.

Average month of birth Famines tend to be most severe during the winter months. In the northern hemisphere, this reduces fertility disproportionately in the later half of the calendar year, thereby lowering the average month of birth [Stein et al., 1975]. ${ }^{6}$ This proxy applied to the 2000 Census indicates 1960 was the worst year for mainland China, Figure 2 (i.e. consistent with the mortality data). Because emigrants to Hong Kong were a highly selected group, both geographically (the Famine hit bordering provinces later) and due to the particular migration policies in place (further described in

\footnotetext{
${ }^{6}$ Authors' tabulation of appendix table 4 data in Stein et al. [1975].
} 
Section 3.5), we cannot rely on mainland mortality data in the Hong Kong analysis. To obtain a proxy for when the Famine peaked for this group of immigrants, we use average month of birth. This proxy indicates 1961 as the worst Famine year for Hong Kong mothers born on the mainland, Figure 3. As expected of the "control group," there was no corresponding change for Hong Kong natives, Figure 4.

\section{Results}

\subsection{Descriptive Results}

We begin by presenting unadjusted outcomes by quarter of birth (for all Chinese) in the four panels of Figure 5. These figures indicate that those born around 1960 had worse socio-economic outcomes than the cohort trend would predict. Recall that this cohort was in utero during the period with the highest death rate, as measured by the weighted death rate (Figure 1). In 2000, the 1960 birth cohort was more likely to be: (1) not working at the time of the Census; (2) supported by other household members; (3) living in a smaller home and; (4) parents of female children. For some of these outcomes, departures from the cohort trend appear in

the flanking/adjacent cohorts as well. This corresponds to the 1959-1961 duration of the Famine, with a peak in 1960. 


\section{$3.2 \quad$ Regression Results}

To investigate systematically how adult outcomes vary with prenatal Famine exposure, we focus on the cohorts born 1956-1964 and estimate by OLS:

$$
y_{i t}=\beta_{0}+\theta \cdot \mathbf{a w d r}_{t}+\beta_{1} \cdot \mathrm{YOB}+\beta_{2} \cdot \mathrm{YOB}^{2}+\beta_{3} \cdot \mathrm{YOB}^{3}+\lambda_{\text {province }}+\varepsilon_{i t},
$$

where $y_{i t}$ denotes the outcome for individual $i$ born in period $t$, $\mathbf{a w d r}_{t}$ denotes the aggregate weighted death rate by birth year and month of birth $t,{ }^{7}$ and YOB denotes birth year. We enter YOB as a cubic to control for the non-linear cohort/age effects apparent in the four panels of Figure 5. Finally, we include a vector of province dummies, $\lambda_{\text {province }}$. Thus (1) allows for a flexible cohort profile within a narrowly-defined birth interval, and assesses whether the prenatal death rate contributes additional explanatory power, as reflected by $\hat{\theta}$. We estimate equation (1) separately for men and women. We do not include dummies for the month of birth, given its apparent endogeneity in Figure $2 .{ }^{8}$

Results from estimating (1) for 2000 Census outcomes are reported in Tables 1-3. Table 1 shows a consistent, negative effect of prenatal Famine exposure on labor market outcomes. Greater famine intensity is associated with a higher likelihood of being illiterate and not working. During the Famine, awdr increased by 1.2 percentage points, implying, e.g., that the most Famine exposed cohorts were $7.5 \%(0.5052 \times 0.012 / 0.081)$ [women] and 9\% $(0.1585 \times 0.012 / 0.021)[\mathrm{men}]$ more likely to be illiterate;

$3 \%(0.4714 \times 0.012 / 0.189)$ [women] and $5.9 \%(0.4017 \times 0.012 / 0.082)[\mathrm{men}]$

\footnotetext{
${ }^{7}$ See Section 2.1 .

${ }^{8}$ Inclusions of month of birth dummies does not alter the basic results from estimating (1) and (2).
} 
more likely to not work; and $13 \%(0.0448 \times 0.012 / 0.004)$ [women] more likely to be disabled. Men in utero during Famine were 9\% more likely to be supported financially by other household members ("Dependent"), and women were $4 \%$ more likely to be supported.

The census does not have any direct measure of earnings, but there is information on housing, which may serve as a proxy for income and wealth. Thus measured, greater fetal Famine exposure also reduced adult economic status.

We also estimate equation (1) using the marriage market variables as outcomes (Table 2). While marriage was nearly universal for women, inspection of who they married reveals that Famine exposed women married men with less education. For men, both the extensive and intensive margins were affected. Men were $6.5 \%(0.4902 \times 0.012 / 0.09)$ more likely to be unmarried and were $8.2 \%(0.2676 \times 0.012 / 0.039)$ more likely to have never married. Moreover, they married at older ages (1.5 months) and were 0.7 $\%(0.5145 \times 0.012 / 0.87)$ less likely to head their households.

The poor outcomes we find on the marriage market do not appear to be driven by conventional supply and demand factors. As cohorts born during the Famine were substantially smaller, ${ }^{9}$ the "marriage squeeze" tended to work in their favor. Using the CHNS, 1982 survey, and 1982 Census data, Porter [2007] finds the "marriage market sex ratio" bottomed out for the 1961 or 1962 birth cohorts (depending on the age-distribution of potential spouses assumed) suggesting poor marital outcomes for women

\footnotetext{
${ }^{9}$ For both men and women, the three smallest cohorts 1950-1970 were those born 1959-1961.
} 
born in these years. But in the 2000 Census, women born in 1960 were the least likely to be married of any cohort born 1956 to 1970, timing more consistent with "fetal origins". For men, marriage rates were reduced for the 1958 and 1960 birth cohorts (results available from authors). While the low marriage rates for the 1958 cohort of men may be attributable to the small number of girls born in the following years (see figure 4 in Porter [2007]), the 1960 decrease in marriage rates is more consistent with a "fetal origins" explanation. ${ }^{10}$

Prenatal famine exposure also raised male (relative to female) mortality as evidenced by survival around age 40. The most exposed cohort was $1.5 \%$-age points $(1.3147 \times 0.012)$ more female (Table 3 , column 1$)$. The most striking finding, however, is that prenatally exposed women bore more girls, the offspring of the most Famine exposed were 0.4\%-age points $(0.3194 \times 0.012)$ less male (column 2). ${ }^{11}$ To anticipate results, the Hong Kong data (derived from birth certificates) will corroborate this pattern.

\subsection{Geographic variation in Famine intensity}

The second test of our hypothesis isolates the geographic variation in the Famine and makes comparisons exclusively within annual birth cohorts. This approach reduces the potential for confounding from later-life events with age-specific effects (e.g. if the Cultural Revolution, launched in 1966,

\footnotetext{
${ }^{10}$ Poor marriage outcomes for the 1960 birth cohort also correspond to regional variation in Famine severity (see Section 3.3); adding cohort size as a control to equation (2) does not substantially affect our estimates.

${ }^{11}$ Similar results are obtained when the logit transform of the proportion of male children is the dependent variable.
} 
delayed school entry among six-year olds). Here, confounding by such later-life events would require their geographic variation to mirror the Famine (while also replicating the Famine's cohort effects). We estimate by OLS:

$$
y_{i t j}=\beta_{0}+\theta \cdot \mathbf{w d r}_{t j}+\gamma_{y o b}+\lambda_{\text {province }}+\varepsilon_{i t j},
$$

where $\theta$ is the parameter of interest, $t$ denotes year and month of birth and $j$ the province of birth. The mortality rate is the weighted death rate $\left(\mathbf{w d r} \mathbf{r}_{j t}\right)$ previously described for the individual's birth date (year and month) and province of birth. As in equation (1), we include vectors of province of birth dummies ( $\left.\lambda_{\text {province }}\right)$, and, as the goal is to isolate the geographic variation in health induced by the Famine, we absorb the average differences for each birth year by including a vector of year of birth dummies $\left(\gamma_{y o b}\right)$.

Results from estimating (2) provide qualitatively distinct evidence that regional differences in malnutrition impact outcomes in adulthood (Tables 4-6). Table 4 shows that local famine severity indeed corresponds to the magnitude of damage in Census outcomes. Women born in high-Famine areas had larger increases in disability rates and larger reductions in house sizes. For men, differences in literacy, work status, disability, and house size correspond to Famine severity in the expected direction.

The magnitude of damage obtained from estimating (2) is generally either similar to that found with (1), or somewhat smaller. Famine-exposed women were again about $13 \%(0.049 \times 0.012 / 0.004)$ more likely to be disabled, and the corresponding figure for men was $12 \%(0.049 \times 0.012 / 0.006)$. 
As for housing, the Famine is estimated to reduce the residence size by slightly under 1 square meter $(58.95 \times .012)$, with a similar effect for men. For men, illiteracy increased $7 \%$ and the likelihood of not working increased $2.4 \%$.

Again, men from high-Famine areas were less likely to be married (3.5\%), more likely to never have married (5\%), married older (.8 months), and were less likely to head their households (.7\%) (Table 5). For women, the point estimates have the expected signs, but are not statistically significant. Finally, Table 6 shows that coefficients for the sex ratio are significant in the expected direction, but roughly one-third the size of the corresponding estimates in Table 3.

Rural versus urban We also estimate the above models separately for those born in rural versus urban regions. We find a Famine effect on the labor and marriage market outcomes for both areas, although the effects for the rural sample were larger (presumably reflecting the greater severity of the Famine in rural areas). For both rural and urban areas, we find that the Famine reduced the sex ratio of the in utero cohort and again in the next generation (results available from authors).

Province of residence Finally, we note that estimates reported in Tables 1-6 are essentially unchanged when fixed effects for the 2000 province of residence are included along with the province of birth dummies. 


\subsection{Potential Biases}

As the Famine both raised mortality and reduced fertility, Famine cohorts were approximately $25-50 \%$ smaller than neighboring cohorts in the 2000 Census. To the extent that Famine-induced mortality was negatively selective, as would seem most plausible (especially insofar as health is concerned), estimates of damage to survivors are downward biased.

Negative selection into fertility is a greater potential concern, since this could generate the appearance of effects absent any true damage (i.e., upward bias). However, historical evidence suggests that the Famine, unlike the subsequent Cultural Revolution, hit poorer individuals the hardest (see, e.g., Cai and Feng [2005]). The Dutch Famine provides further evidence: fathers of children conceived in the winter of 1944-45 were more likely to have non-manual occupations [Stein et al., 1975].

Direct evidence on selection into fertility is available from the China Fertility surveys (conducted in 1985 and 1988), which include information on the respondent's mother's educational attainment (further information in the Appendix). Plotting the share of women whose mothers had no education, primary or less, secondary or more, or who did not know their mother's education, the 1959-61 birth cohorts do not appear any worse than adjacent cohorts (Figure 6). If anything, the 1959-61 birth cohorts had mothers with more education than adjacent cohorts.

Cohorts born during 1962 to 1964 did not directly experience the Famine, and in this respect may constitute a better control group for the Famine exposed cohorts than those born in the 1950s (who were exposed to higher mortality rates and malnutrition in childhood). Re-estimating 
equations (1) and (2) on the sample restricted to birth cohorts 1959-1964, we obtain similar, if not slightly stronger, results (available on request).

Another possible source of bias is that those born during famines may be born to inherently more fecund women or parents who have a stronger desire for many offspring, and possibly, less interest in the quality of each individual child. Whereas we cannot control for parental preferences (other than note as above, that the maternal education of the Famine cohorts was if anything better than that of adjacent cohorts), we can investigate sibship size using a recent survey: The 2005 Urban Chinese Education and Labor Survey conducted by the Ministry of Education in 12 cities in China, covering some 10,000 households. ${ }^{12}$ The $1959-61$ cohorts do not appear to have more siblings, as seen in Figure 7. Rather, these birth cohorts are on a negative trend (linear and decreasing in year of birth). ${ }^{13}$

\subsection{Birth Outcomes in Hong Kong}

A shortcoming of the analysis using the 2000 (mainland) Census is the want of a truly unexposed control group. Hong Kong Natality data offer a potential solution to this problem. Communist China severely restricted

\footnotetext{
${ }^{12}$ The 2000 census does not have information on sibship size. Neither can it be inferred from the relationship variable for a household, since most adult siblings live in different households. Finally, the earliest publicly available Chinese census was conducted in 1982, when the 1959-1961 cohorts were in their early 20s.

${ }^{13}$ This is confirmed by a regression of sibsize on a dummy for birth cohorts 1959-61, controlling for a linear trend in birth year. The coefficient on this dummy is about zero, with a very large standard error (not reported).
} 
out-migration. This policy was, however, temporarily and dramatically suspended during a six-week period in the spring of 1962 when a large number of mainlanders entered Hong Kong [Burns, 1987]. Among the refugees were mainland born children, who themselves show up as parents in the 1984-2004 Hong Kong Natality files.

The migration of mainland residents to Hong Kong, during and in the years after the Famine, provides a common environment for those affected by the Famine (mainland immigrants) and those who were not (Hong Kong born).

The Hong Kong Natality microdata allow us to focus on second generation birth outcomes, specifically low birth weight and sex of offspring. Low birth weight may be a negative outcome because it is a correlate of poor adult health and economic performance. As for sex of offspring, a daughter may not be a poor outcome. Still, it may signal poor parental condition; see Section 4.

We estimate a modified version of equation (1) separately on the sub samples of mainland born and Hong Kong born mothers giving birth in Hong Kong 1984-2004. Based on the dramatically lower average month of birth among mainland born mothers born in 1961 (Figures 3 and 4), we substitute the dummy variable I (1961), which takes on the value $1 / 100$ for those born in 1961, for the death rate $\left(\mathbf{a w d r}_{t}\right)$.

A dummy for the sex of the child is also included when the dependent variable is birth weight since males are on average heavier than females. The birth interval is shifted forward one year from the mainland Census regressions, that is, we focus on births to parents themselves born 
1957-1965. Furthermore, we restrict the sample to singleton births. We find that mothers born in 1961 were $8 \%(0.247 / 0.030)$ more likely to give birth to a child of low birth weight (less than 2,500 grams) and $1.2 \%$ $(0.00629 / 0.52)$ less likely to give birth to a son than mothers born in adjacent years (Table 7). No significant effects were detected for the Hong Kong born mothers, despite their greater numbers.

\section{Summary and Discussion}

We have used the 1959-1961 Chinese famine as a natural experiment in fetal nutrition. Higher Famine intensity - as indicated by time or place of birth - was associated with greater risk of being illiterate, out of the labor force, marrying later (men), and marrying spouses with less education (women). To the extent that selection into childbearing during the Famine was positive (as maternal education and previous research would suggest), our estimates of long-term damage are conservative.

Because the nutritional status of pregnant women continues to lag other demographic groups in many developing countries, our findings remain relevant. In addition, historical nutritional deprivation may impede adult outcomes today in developed countries. For example, Almond et al. [2007] found improvements in birth outcomes (including birth weight) with the introduction of the Food Stamps Program during the 1960s in the U.S., particularly among Black infants. These cohorts also manifested improved outcomes in adulthood [Almond and Chay, 2006].

Perhaps the most intriguing result is that Famine exposure lowered the 
sex ratio of not only the first but also the second generation. Prenatally exposed women were themselves more likely to bear daughters. This profemale effect is all the more noteworthy given the well documented prevalence of son preference in mainland China. Famine-induced reductions in the sex ratio are consistent with empirical work finding lower sex ratios for unmarried or poorly educated mothers [Almond and Edlund]. While the magnitude of the Famine's effect on the sex ratio may appear small, it is several times the larger than that associated with marital status in U.S. natality data [Almond and Edlund] and is similar to differences between mothers reporting living with a partner around the time of conception in survey data and those who did not [Norberg, 2004]. Thus, small changes in the sex ratio can reflect large differences in maternal circumstance.

Trivers and Willard [1973] proposed that evolution would favor parental ability to vary the sex ratio of offspring according to condition: parents in poor condition would favor daughters and parents in good condition would favor sons. Their argument was based on the observation that while the average number of offspring to males and females equalizes (assuming balanced sex ratios), the reproductive success of a male offspring tends to be more resource-sensitive. Maternal malnutrition has been observed to correlate with more female births, (see, e.g., Andersson and Bergström [1998]). Pathways include heightened rates of male fetal deaths, as was found to be the case during the Dutch famine [Roseboom et al., 2001a]. Another possibility is that starvation affects early cell division of male and female embryos differentially [Cameron, 2004].

To our knowledge, ours is the first large scale quasi-experimental evi- 
dence of a Trivers-Willard effect in human populations. It is also the first evidence (quasi-experimental or otherwise) of an intergenerational "echoeffect" of maternal nutritional status on the sex ratio (to our knowledge). That these changes in the sex ratio parallel larger movements in socioeconomic outcomes suggest the cohort sex ratio as a readily-measured proxy for maternal conditions prior to birth. 


\section{References}

Douglas Almond and Kenneth Y. Chay. The long-run and intergenerational impact of poor infant health: Evidence from cohorts born during the civil rights era. Manuscript, UC Berkeley Department of Economics, February 2006.

Douglas Almond and Lena Edlund. Trivers-Willard at birth and one year: Evidence from U.S. natality data 1983-2001. Proceedings of the Royal Society B: Biological Sciences. Forthcoming.

Douglas Almond, Hilary W. Hoynes, and Diane Whitmore Schanzenbach. The impact of the food stamp program on infant outcomes. Manuscript, UC Davis, June 2007.

Roland Andersson and Staffan Bergström. Is maternal malnutrition associated with a low sex ratio at birth? Human Biology, 70(6):1101-1106, December 1998.

D.J.P. Barker, editor. Fetal and Infant Origins of Adult Disease. British Medical Journal, London, 1992.

Otto P. Bleker, Tessa J. Roseboom, Anita C.J. Ravelli, Gert A. van Montfans, Clive Osmond, and David J.P. Barker. The Impact of Maternal Nutrition on the Offspring: Nestle Nutrition Workshop Series Pediatric Program, Vol. 55, pages 183-195. "Cardiovascular Disease in Survivors of the Dutch Famine". Karger, Basel, Switzerland, 2005.

John P. Burns. Immigration from China and the future of hong kong. Asian Survey, 27(6):661-682, June 1987.

Yong Cai and Wang Feng. Famine, social disruption, and involuntary fetal loss: Evidence from Chinese survey data. Demography, 42(2):301-322, May 2005.

Elissa Z. Cameron. Facultative adjustment of mammalian sex ratios in support of the Trivers-Willard hypothesis: Evidence for a mechanism. Proceedings of the Royal Society B: Biological Sciences, 271(1549):17231728, 2004.

Anne Case, Darren Lubotsky, and Christina Paxson. Economic status and health in childhood: The origins of the gradient. American Economic Review, 92(5):1308-1334, December 2002.

Yuyu Chen and Li-An Zhou. The long term health and economic consequences of 1959-1961 famine in China. Journal of Health Economics, 26 (4):659-681, July 2007. 
China Statistical Press. Comprehensive statistical data and materials on 50 years of new china. Technical report, China Statistical Press, Beijing, China, 2000.

David St Clair, Mingqing Xu, Peng Wang, Yaqin Yu, Yoorong Fang, Feng Zhang, Xiaoying Zheng, Niufan Gu, Guoyin Feng, Pak Sham, and Lin He. Rates of adult schizophrenia following prenatal exposure to the Chinese famines of 1959-1961. Journal of the American Medical Association, 294(5):557-562, August 2005.

David M. Cutler, Angus S. Deaton, and Adriana Lleras-Muney. The determinants of mortality. The Journal of Economic Perspectives, 20(3): 97-120, March 2006.

L. F. DeRose, M. Das, and S.R. Millman. Does female disadvantage mean lower access to food? Population and Development Review, 26(3):517547, September 2000.

Tue Gorgens, Xin Meng, and Rhema Vaithianathan. Stunting and selection effects of famine: A case study of the great Chinese famine. WorkingPaper, Australian National University, May 2005.

Wei Li and Dennis Tao Yang. The Great Leap Forward: Anatomy of a central planning disaster. Journal of Political Economy, 113(4):840-877, August 2005.

Justin Yifu Lin. Collectivization and China's agricultural crisis in 19591961. Journal of Political Economy, 98(6):1228-1252, December 1990.

Justin Yifu Lin and Dennis Tao Yang. Food availability, entitlement and the Chinese famine of 1959-61. Economic Journal, 110(460):136-158, January 2000.

Zhehui Luo, Ren Mu, and Xiaobo Zhang. Famine and overweight in China. Review of Agricultural Economics, 28(3):296-304, Proceedings 2006.

Xin Meng and Nancy Qian. The long run impact of childhood malnutrition: Evidence from China's great famine. November 28, Working Paper, Brown University, 2006.

Stephen E. Morgan. The welfare consequences of the Great Leap Forward in China, 1959-1961: The stature of the survivor. manuscript, University of Melbourne, 2006.

Richard Neugebauer, Hans Wijbrand Hoek, and Ezra Susser. Prenatal exposure to wartime famine and development of antisocial personality disorder in adulthood. Journal of the American Medical Association, 281(5):455-462, August 1999. 
Karen Norberg. Partnership status and the human sex ratio at birth. Proceedings of the Royal Society B: Biological Sciences, 271(1555):24032410, 2004.

Xizhe Peng. Demographic consequences of the Great Leap Forward in China's provinces. Population and Development Review, 13(4):639-670, December 1987.

Maria Porter. The effects of sex ratio imbalance on marriage \& household decisions. Manuscript, University of Chicago, July 2007.

Kathleen Maher Rasmussen. The "fetal origins" hypothesis: Challenges and opportunities for maternal and child nutrition. Annual Review of Nutrition, 21:73-95, July 2001.

Tessa J. Roseboom, Jan H.P. Meulen, Clive Osmond, David J.P. Barker, Anita C.J. Ravelli, and Otto P. Bleker. Adult survival after prenatal exposure to the Dutch famine. Paediatric and Perinatal Epidemiolgy, 15(3):220-225, July 2001a.

Tessa J. Roseboom, Jan H.P. Meulen, Anita C.J. Ravelli, Clive Osmond, David J.P. Barker, and Otto P. Bleker. Effects of prenatal exposure to the Dutch famine on adult disease in later life: An overview. Twins Research, 4(5):293-298, October 2001b.

Xinzheng Shi. Does famines have long term effects? evidence from china. University of Michigan, June 2006.

Zena Stein, Mervyn Susser, Gerhart Saenger, and Francis Marolla. Famine and Human Development: The Dutch Hunger Winter of 1944-1945. Oxford University Press, New York, 1975.

Robert L. Trivers and Rob E. Willard. Natural selection and the ability to vary the sex ratio of offspring. Science, 179(4068):90-92, January 1973.

Susan P. Walker, Theodore D. Wachs, Julie Meeks Gardner, Betsy Lozoff, Gail A. Wasserman, Ernesto Pollitt, Julie A. Carter, and the International Child Development Steering Group. Child development: Risk factors for adverse outcomes in developing countries. The Lancet, 369: 145-157, January 132007.

Lijing Yan. Height, Health, and Hazards: Reconstructing Secular Trends in Stature in Twentieth Century China. PhD thesis, UC Berkeley, 1999. An earlier version presented at the annual meeting of the Population Association of America on March 26, 1999 in New York City.

Shujie Yao. A note on the causal factors of China's famine in 1959-1961. Journal of Political Economy, 107(6):1365-1369, December 1999. 


\section{Appendix}

\section{Variable Definitions:}

\section{Census 2000}

wdr Weighted death rate for the gestation period, assuming 9 month gestation, and province of birth. For example, a person born in January 1960 in Beijing is assigned 1/9th of Beijing's 1960's mortality rate and 8/9th of Beijing's 1959's mortality rate.

awdr Aggregate weighted average death rate, the wdr collapsed by month and birth year. Thus, it is the population weighted mean of wdr by month and year of birth.

mean Mean of dependent variable.

Province The province of birth. Our results are robust to inclusion of dummies for province of residence.

Illiterate Dummy indicating that the respondent was either illiterate or semi-literate.

Don't work Dummy indicating that the person did not work for more than 1 hour between October 25 and October 31 (in 2000). This includes those who are on leave from a job, as well as non-workers.

On leave from job Not working because on leave, training, or seasonal lay-off.

Supported by other HH members (Dependent) Main income source was support by other household members.

Disabled Dummy indicating that the person does not work because he/she has "lost ability to work."

House area Area of home, in square meters.

Unmarried Dummy indicating that the respondent was unmarried at the time of the census.

Never married Dummy indicating that the respondent had never married.

Spousal education Includes head-spouse couples only. Education is in years.

Marriage age Age in months at time of first marriage. 
Household head Dummy indicating that the respondent was household head. Includes only respondents living in "family type" households (as opposed to "collectives").

Male Dummy indicating that the respondent is male.

Sons/Kids Fraction sons among ever borne children. Excludes women who had not borne any children.

No kid Dummy indicating that the woman had borne no children.

Child mortality Number of children ever borne minus number of surviving children (at the time of the census) divided by the number of children ever borne, by year and quarter of birth of mother.

\section{Hong Kong Natality data}

I(1961) Dummy indicating that the mother was born in 1961, scaled by $1 / 100$.

Low BWT Low birth weight. Dummy indicating that child weighed less than 2,500 grams at birth.

China Dummy for whether born in mainland China.

\section{China Fertility Surveys}

The China Fertility surveys were carried out in 1985 and 1987 in the following provinces: Hebei, Shaangxi, Liaoning, Guangdong, Guizhou, Gansu; and the municipalities of Beijing and Shanghai. (We have not been able to access data for Shandong.) In total, some 46,000 ever-married women between 15-49 years of age were interviewed, providing detailed information on pregnancy history. These data are available from the Office of Population Research, Princeton University, http://opr.princeton.edu/Archive/cidfs/. 
Table 1: 2000 Census: Labor and Housing Outcomes for 19561964 Birth Cohorts

\begin{tabular}{llllll}
\hline \hline & Illiterate & Don't work & Disabled & Dependent & House area \\
\hline \multirow{5}{*}{ mean } & 0.081 & 0.189 & 0.004 & 0.119 & 87.162 \\
\cline { 2 - 6 } awdr & $0.5052^{* *}$ & $0.4714^{* * *}$ & $0.0448^{*}$ & $0.3972^{* * *}$ & $-220.1528^{* * *}$ \\
& {$[0.2169]$} & {$[0.1530]$} & {$[0.0250]$} & {$[0.1354]$} & {$[48.4753]$} \\
$N$ & 786156 & 786156 & 786156 & 786156 & 772260
\end{tabular}

$\underline{\text { Men }}$

\begin{tabular}{llllll} 
mean & 0.021 & 0.082 & 0.006 & 0.019 & 83.933 \\
\cline { 2 - 6 } awdr & $0.1585^{*}$ & $0.4017^{* * *}$ & 0.0657 & $0.1399^{* *}$ & $-104.7566^{* *}$ \\
& {$[0.0784]$} & {$[0.1131]$} & {$[0.0426]$} & {$[0.0674]$} & {$[38.3963]$} \\
$N$ & 818103 & 818103 & 818103 & 818103 & 790342 \\
\hline
\end{tabular}

awdr - aggregate weighted death rate by birth year and month.

mean - mean of dependent variable.

Standard errors clustered at province of birth in square brackets. ${ }^{*}$ significant at $10 \%$; ** significant at $5 \%$; ** significant at $1 \%$. 
Table 2: 2000 Census, Marriage Market Outcomes, 1956-1964

\section{Birth Cohorts}

\begin{tabular}{|c|c|c|c|c|c|}
\hline & Unmarried & Never married & Spousal ed. ${ }^{a}$ & Marriage age $^{b}$ & Household head $^{c}$ \\
\hline & \multicolumn{5}{|c|}{$\underline{\text { Women }}$} \\
\hline mean & 0.061 & 0.004 & 9.057 & 269.237 & 0.118 \\
\hline \multirow[t]{2}{*}{ awdr } & 0.2608 & -0.0013 & $-6.3342^{* *}$ & $67.4994^{* *}$ & -0.0998 \\
\hline & {$[0.1632]$} & {$[0.0249]$} & {$[2.4652]$} & {$[28.5417]$} & {$[0.1633]$} \\
\hline \multirow[t]{2}{*}{$N$} & 786156 & 786156 & 685989 & 783015 & 786156 \\
\hline & \multicolumn{5}{|c|}{$\underline{\text { Men }}$} \\
\hline mean & 0.090 & 0.039 & 8.060 & 290.898 & 0.870 \\
\hline \multirow[t]{2}{*}{ awdr } & $0.4902^{* * *}$ & $0.2676^{* *}$ & -0.1692 & $125.1309^{* * *}$ & $-0.5145^{* *}$ \\
\hline & {$[0.1285]$} & {$[0.1035]$} & {$[2.5349]$} & {$[28.5395]$} & {$[0.2302]$} \\
\hline$N$ & 818103 & 818103 & 683041 & 785927 & 818103 \\
\hline
\end{tabular}

awdr - aggregate weighted death rate by birth year and month.

mean - mean of dependent variable.

${ }^{a}$ Includes head-spouse couples only. Education is in years.

${ }^{b}$ Marriage age is in months.

${ }^{c}$ Includes those residing in family units (i.e., excludes those residing in collectives).

Standard errors clustered at province of birth in square brackets. ${ }^{*}$ significant at $10 \%$; ** significant at $5 \%$; ** significant at $1 \%$. 
Table 3: 2000 Census: Sex Ratio outcomes, 1956-1964 Birth Cohorts

\begin{tabular}{llll}
\hline \hline & & \multicolumn{2}{c}{ Women $^{b}$} \\
\cline { 3 - 4 } & Male $^{a}$ & Sons/Kids & No child \\
mean & 0.51 & 0.548 & 0.007 \\
\hline awdr & $-1.3147^{* * *}$ & $-0.3194^{* *}$ & 0.0712 \\
& {$[0.2651]$} & {$[0.1368]$} & {$[0.0503]$} \\
$N$ & 1604259 & 773291 & 786156 \\
\hline \hline
\end{tabular}

awdr - aggregate weighted death rate by birth year and month.

mean - mean of dependent variable.

${ }^{a}$ Dummy - equals 1 if respondent was male.

${ }^{b}$ Pertains to children borne.

Standard errors clustered at province of birth in square brackets. * significant at $10 \%$; ** significant at $5 \% ; * * *$ significant at $1 \%$. 
Table 4: 2000 Census: Cross-sectional Variation in Famine Severity, Labor Market and Housing Outcomes, 1956-1964 Birth Cohorts

\begin{tabular}{llllll}
\hline & Illiterate & Don't work & Disabled & Dependent & House area \\
\hline \multirow{5}{*}{$\mathbf{w d r}$} & 0.1659 & 0.0953 & $0.0418^{* * *}$ & 0.0755 & $-58.9501^{* *}$ \\
\cline { 2 - 6 }$N$ & {$[0.1269]$} & {$[0.1657]$} & {$[0.0116]$} & {$[0.0917]$} & {$[22.0095]$} \\
\multirow{2}{*}{$N$} & 764786 & 764786 & 764786 & 764786 & 751352 \\
& & & & & \\
& & & & \\
wdr & $0.1231^{*}$ & $0.1628^{* *}$ & $0.0585^{* * *}$ & 0.0321 & $-52.1040^{*}$ \\
& {$[0.0688]$} & {$[0.0666]$} & {$[0.0170]$} & {$[0.0376]$} & {$[28.5949]$} \\
$N$ & 795408 & 795408 & 795408 & 795408 & 768522 \\
\hline
\end{tabular}

$\overline{\text { Standard errors clustered at province of birth in square brackets. }{ }^{*} \text { signif- }}$ icant at $10 \%$; ${ }^{* *}$ significant at $5 \%$; ${ }^{* *}$ significant at $1 \%$. 
Table 5: 2000 Census: Cross-sectional Variation in Famine Severity, Marriage Market Outcomes, 1956-1964 Birth Cohorts

\begin{tabular}{|c|c|c|c|c|c|}
\hline & Unmarried & Never married & Spousal ed. ${ }^{a}$ & Marriage age ${ }^{b}$ & Household head ${ }^{c}$ \\
\hline \multirow{3}{*}{ wdr } & \multicolumn{5}{|c|}{ Women } \\
\hline & 0.0505 & 0.0217 & 0.0794 & 14.7224 & -0.0701 \\
\hline & {$[0.0623]$} & {$[0.0130]$} & {$[1.5906]$} & [19.9378] & {$[0.1297]$} \\
\hline \multirow[t]{2}{*}{$N$} & 764786 & 764786 & 668672 & 761879 & 760726 \\
\hline & \multicolumn{5}{|c|}{ Men } \\
\hline \multirow[t]{2}{*}{ wdr } & $0.2666^{* * *}$ & $0.1555^{* *}$ & 1.5938 & $67.6296^{* * *}$ & $-0.5089^{* * *}$ \\
\hline & {$[0.0696]$} & {$[0.0634]$} & {$[1.3770]$} & [22.8696] & {$[0.1183]$} \\
\hline$N$ & 795408 & 795408 & 665857 & 764670 & 779087 \\
\hline
\end{tabular}

wdr Weighted average death rate for the gestation period, assuming 9

month gestation. Varies by province and month and year of birth.

${ }^{a}$ Includes head-spouse couples only. Education is in years.

${ }^{b}$ Marriage age is in months. ${ }^{c}$ Includes those residing in family units (i.e., excludes those residing in collectives).

Standard errors clustered at province of birth in square brackets. ${ }^{*}$ significant at $10 \%$; ${ }^{*}$ significant at $5 \%$; ${ }^{* *}$ significant at $1 \%$. 
Table 6: 2000 Census: Cross-sectional Variation in Famine Severity, Sex ratio outcomes, 1956-1964 Birth Cohorts

\begin{tabular}{llll}
\hline \hline & & \multicolumn{2}{c}{ Women $^{b}$} \\
\cline { 3 - 4 } & Male $^{a}$ & Sons/Kids & No child \\
\hline wdr & $-0.3264^{* *}$ & $-0.1693^{* *}$ & 0.0325 \\
& {$[0.1390]$} & {$[0.0797]$} & {$[0.0251]$} \\
\multirow{2}{*}{$N$} & 1560194 & 752418 & 764786 \\
\hline \hline
\end{tabular}

${ }^{a}$ Dummy - equals 1 if respondent was male.

${ }^{b}$ Pertains to children borne.

Standard errors clustered at province of birth in square brackets. ${ }^{*}$ significant at $10 \%$; ${ }^{* *}$ significant at $5 \%$; ${ }^{* * *}$ significant at $1 \%$. 
Table 7: 1984-2004 Natality outcomes in Hong Kong: mainland vs Hong Kong born mothers

\begin{tabular}{|c|c|c|c|c|}
\hline \multirow[b]{4}{*}{ mean } & \multicolumn{4}{|c|}{ Mother born: } \\
\hline & \multicolumn{2}{|c|}{ Mainland } & \multicolumn{2}{|c|}{ Hong Kong } \\
\hline & Low BWT ${ }^{a}$ & $\operatorname{Son}^{b}$ & Low BWT ${ }^{a}$ & $\operatorname{Son}^{b}$ \\
\hline & 0.031 & 0.52 & 0.039 & 0.517 \\
\hline \multirow[t]{2}{*}{ I (1961) } & $0.247^{* *}$ & $-0.629 * * *$ & 0.014 & -0.009 \\
\hline & {$[0.099]$} & {$[0.121]$} & {$[0.037]$} & {$[0.074]$} \\
\hline$N$ & 198452 & 198452 & 393419 & 393419 \\
\hline
\end{tabular}

I (1961) - dummy, equals 1/100 if mother born in 1961.

mean - mean of dependent variable.

${ }^{a}$-dummy, equals 1 if birth weight was less than 2,500 grams.

${ }^{b}$-dummy, equals 1 if child male.

Regression results from estimating equation 1 where I(1961) substitutes for awdr and without the province dummies. The birth weight regressions also include a dummy for the sex of the child.

Standard errors clustered by year of birth in square brackets. * significant at $10 \% ; * *$ significant at $5 \% ; * * *$ significant at $1 \%$. 


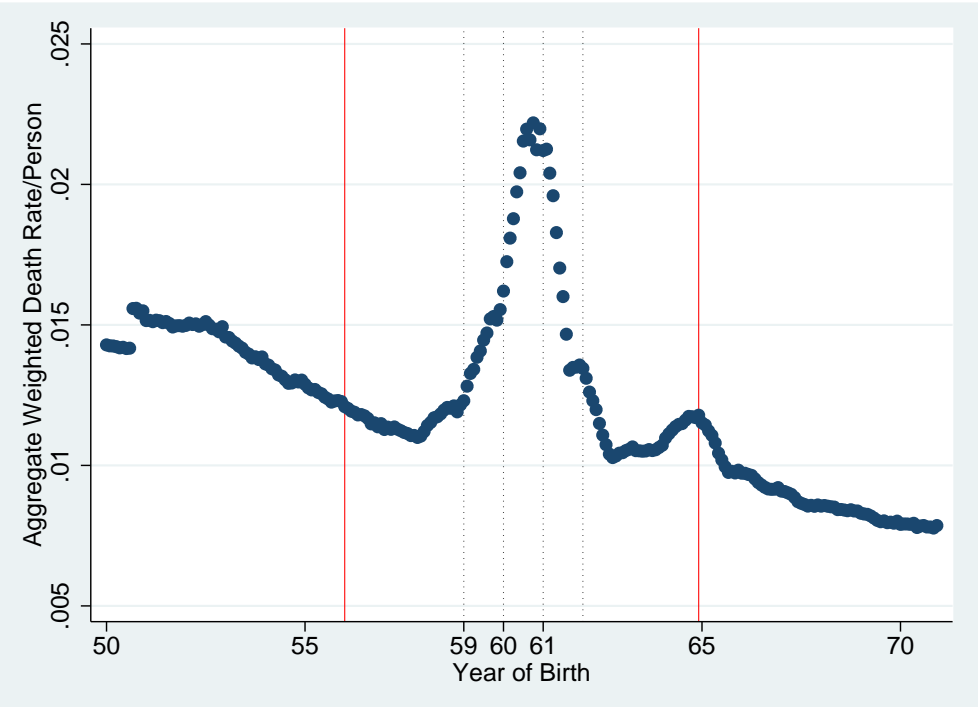

Figure 1: Aggregate Weighted Death Rate by Year and Month of Birth, Mainland China

Note: Authors' calculations based on all age death rates by year and province as reported by China Statistical Press [2000].

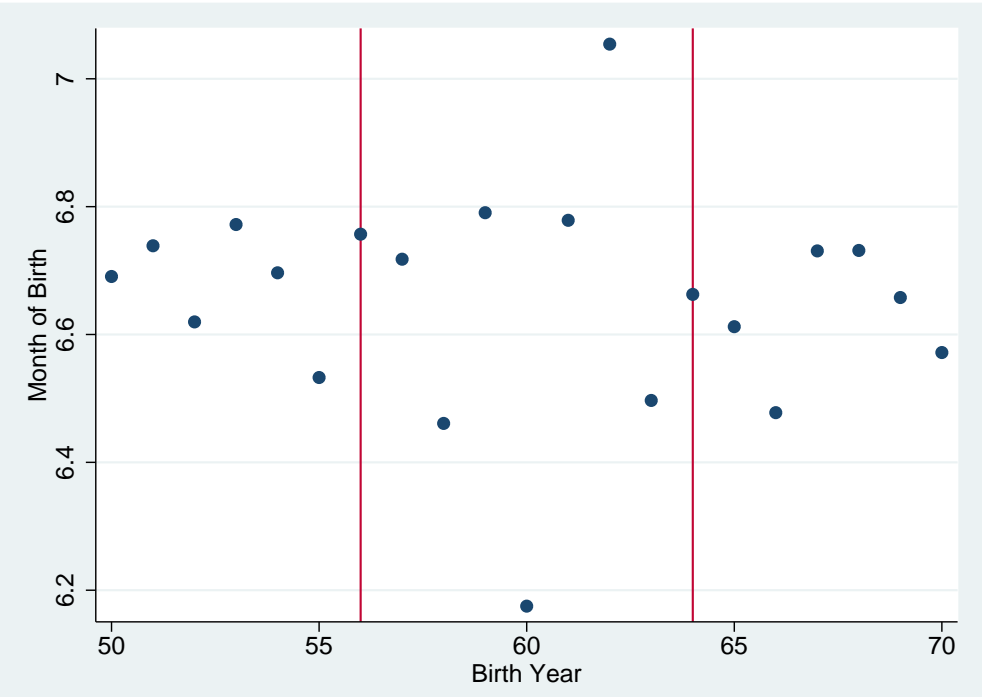

Figure 2: Average Month of Birth, Mainland China

Source: 2000 census. 


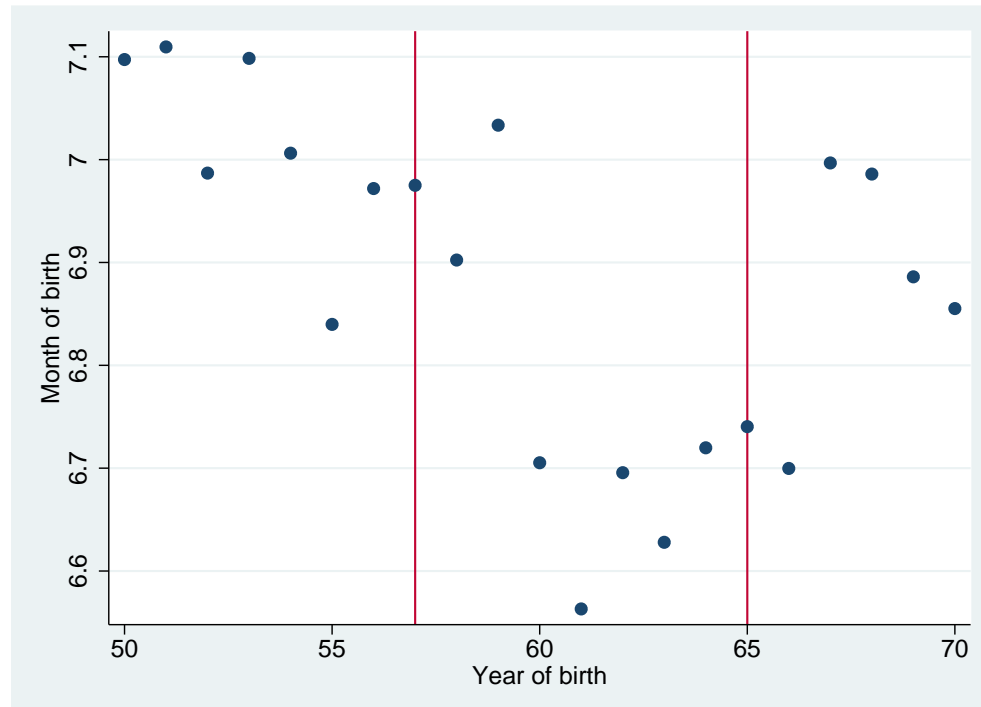

Figure 3: Average month of birth, Hong Kong Mothers born in Mainland

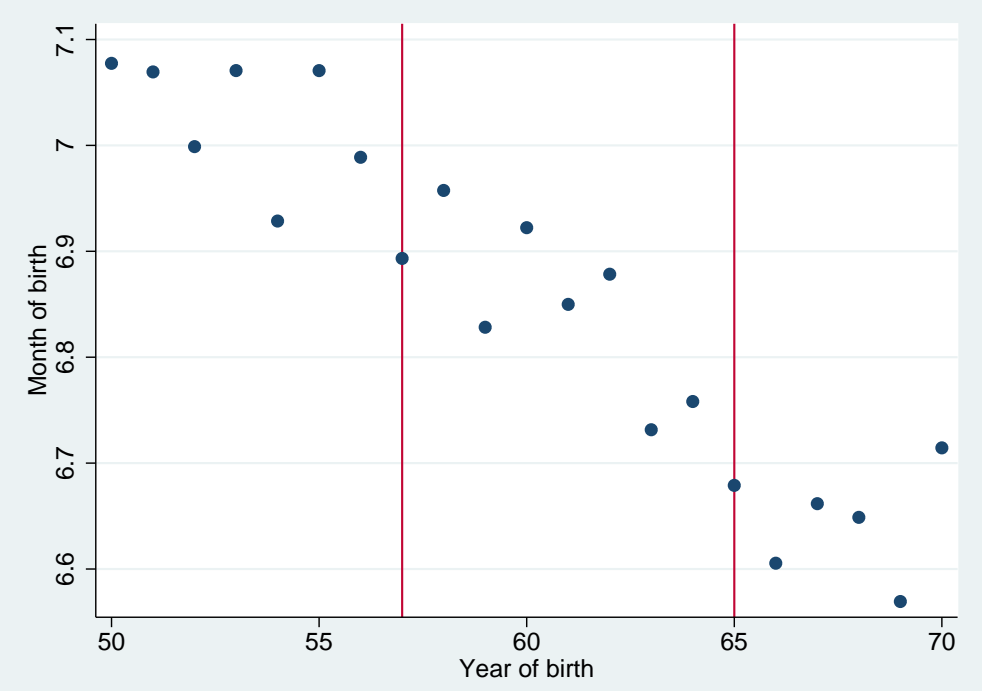

Figure 4: Average month of birth 3 fHong Kong Mothers born in Hong Kong 

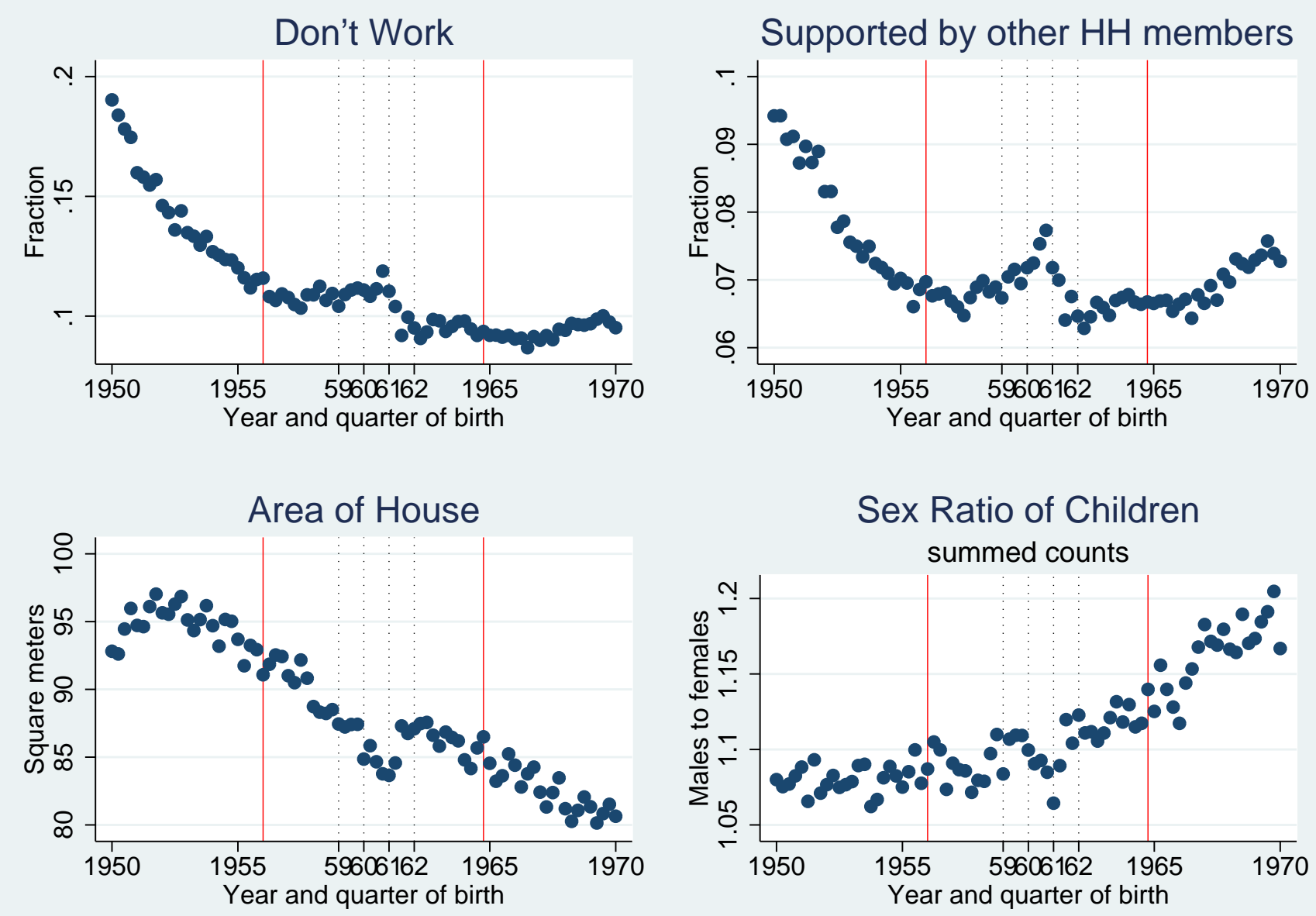

Figure 5: Census outcomes by year and quarter of birth

Source: 2000 census. 

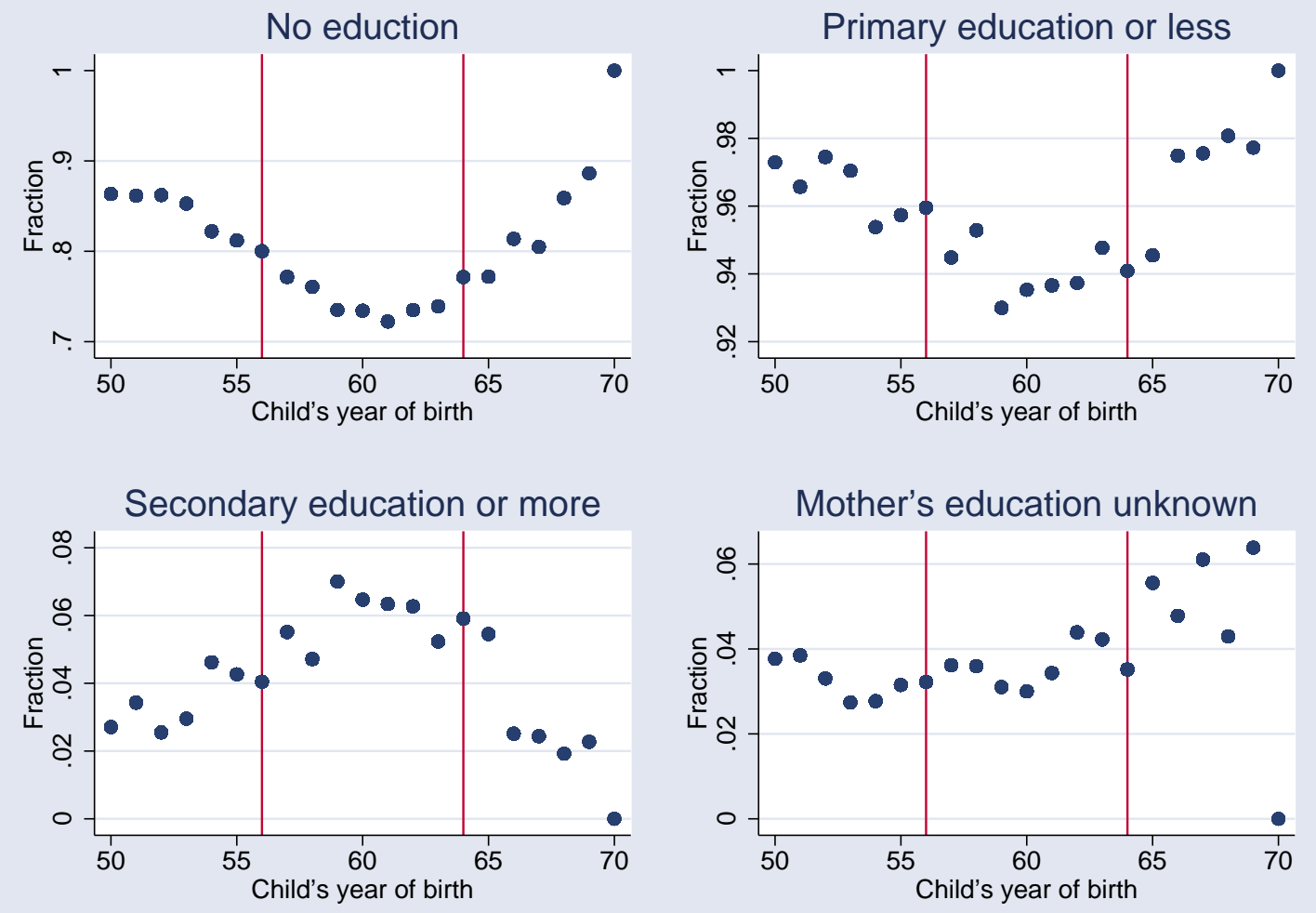

Figure 6: Mother's education by child's (respondent) year of birth Source: China Fertility surveys 1985/87.

Note: For mother's education unknown, the universe is all respondents.

For the remainder, the universe is those who knew their mother's education. 


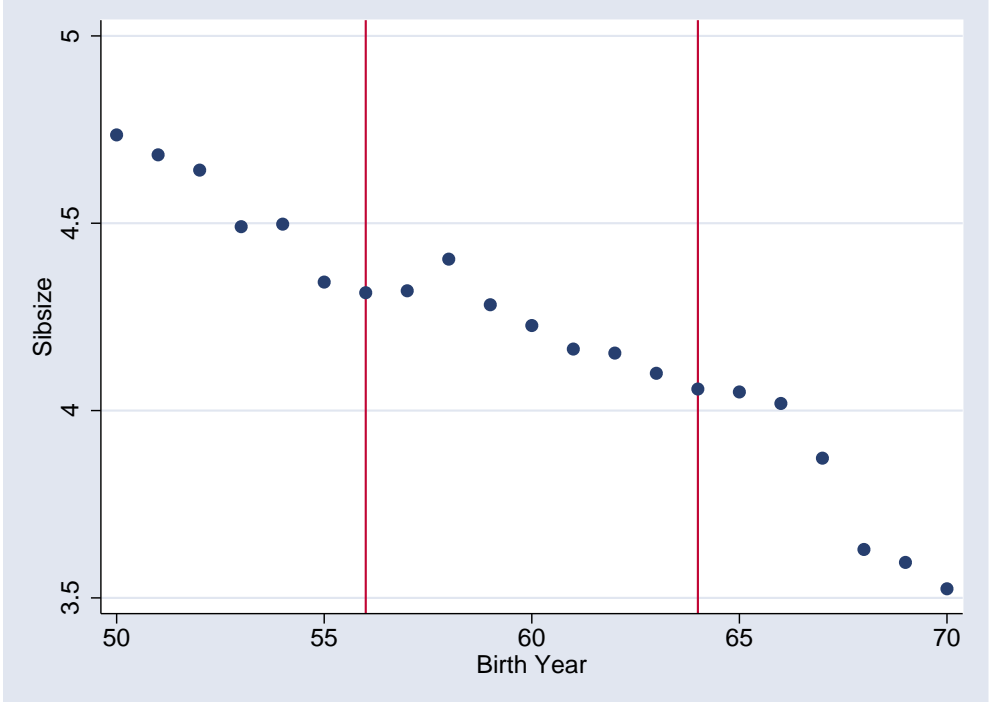

Figure 7: Number of siblings by respondent's year of birth Source: 2005 Urban Chinese Education and Labor Survey. 